\title{
Cherrie Moraga'nın The Hungry Woman: A Mexican Medea Adlı Oyununun Homi Bhabha'nın Postkolonyal Melezlik \& Üçüncü Alan Teorisi Açısından İncelenmesi
}

\section{A Bhabhaian Analysis: The Postcolonial Hybridity and the Third Space in Cherrie Moraga's The Hungry Woman: A Mexican Medea}

\author{
Aycan Gürlüyer ${ }^{1}$ (D)
}

'Öğretim Görevlisi , İstanbul Üniversitesi,

Yabancı Diller Yüksekokulu, İstanbul, Türkiye

ORCID: A.G. 0000-0001-5383-2722

Sorumlu yazar/Corresponding author: Aycan Gürlüyer,

İstanbul Üniversitesi, Yabancı Diller Yüksekokulu Kirazlı Mescit Sk. No: 31 PK:34116 Süleymaniye / Fatih, İstanbul, Türkiye

E-posta/E-mail: aycangurluyer@istanbul.edu.tr

Başvuru/Submitted: 03.11.2019

Revizyon Talebi/Revision Requested:

08.11.2019

Son Revizyon/Last Revision Received:

13.12.2019

Kabul/Accepted: 17.12 .2019

\section{Atıf/Citation:}

Gurluyer, Aycan. "Cherrie Moraga'nın The Hungry Woman: A Mexican Medea Adlı Oyununun Homi Bhabha'nın Postkolonyal Melezlik \& Üçüncü Alan Teorisi Açısından Incelenmesi" Tiyatro Eleştirmenliğive Dramaturji Bölümü Dergisi 29, (2019): 43-63.

https://doi.org/10.26650/jtcd.642087

\section{ÖZ}

Bu çalışmanın amacı, Çağdaş Amerikan Tiyatrosu'nda yer alan Chicana Tiyatrosu'nun öncü feminist yazarlarından şair ve düşünür Cherrie Moraga'nın yeniden yazdığı Medea mitini, Homi Bhabha'nın postkolonyal melezlik ve üçüncü alan teorisi kapsamında ele almaktır. Melezlik kavramını tartışmalı bir kültürel kimlik yapısı içinde değerlendiren Bhabha, sömüren/kolonileştiren ve sömürülen/ kolonileştirilen iki kültürün etkileşimi sonucu melez bir üçüncü alan ortaya çıktığının altını çizer. Moraga'nın distopik oyunu The Hungry Woman: A Mexican Medea'da, anavatanı Aztlan'dan Phoenix'e sürülen başkarakter Medea'nın, oğlunu öldürdükten sonra yaşamını bir akıl hastanesi hapishanesinde geçirmesi anlatılmaktadır. Çalışmada, Bhabha'nın teorisinden yola çıkarak, Chicana yazar Moraga'nın Yunan miti Medea'yı Meksikalı bir lezbiyen kadın olarak yazdığı bu oyunda yarattığı feminist üçüncü alan incelenecektir.

Anahtar Kelimeler: Homi Bhabha, Cherrie Moraga, Postkolonyal Melezlik, Chicano/a Tiyatrosu, Üçüncü Alan Teorisi

\section{ABSTRACT}

The aim of this study is to evaluate the recasting of the Medea myth by Cherrie Moraga, poet, thinker and one of the pioneer feminist playwrights of the Chicana theatre in Contemporary American Drama, under the scope of Homi Bhabha's postcolonial hybridity and the third space theory. Evaluating the concept of hybridity within a controversial cultural identity structure, Bhabha underscores a hybrid third space which comes into being as a result of the fusion of the colonizer and the colonized. In Moraga's dystopian play The Hungry Woman: A Mexican Medea, the protagonist Medea, who is exiled from her homeland Aztlan to Phoenix, and her life in a prison psychiatric unit after killing her son are portrayed.

Through the lens of Bhabha's theory, this paper aims to analyse Moraga's play and examine the feminist third space evoked by the play's main character, a lesbian Mexican woman.

Keywords: Homi Bhabha, Cherrie Moraga, Postcolonial Hybridity, Chicano/a Theatre, the Third Space Theory 


\section{EXTENDED ABSTRACT}

The expansion of the multicultural discourses, theories and art work has produced countless studies in the $20^{\text {th }}$ and $21^{\text {st }}$ centuries. As one of those studies, this paper aims to trace Homi Bhabha's postcolonial hybridity and the third space theory in Cherrie Moraga's apocalyptic play The Hungry Woman: A Mexican Medea (1994). Postcolonial theorist Bhabha considers the concept of hybridity as an identity which is shaped by the fusion of the colonizer and the colonized. According to his theory of postcolonial hybridity, when cultures interact and come into contact with each other, their original states disappear and a hybrid one emerges. Bhabha contends that while this blending of cultures may seem perilous to cultural identity, it can actually be advantageous for growth: cultural production, because of the cultural interblending, may become more creative. He also argues that a newness steps into the world of colonizers and colonized through a new cultural space which generates the third space. To him, hybridity does not only hold the traces of two cultures, but it also forms a third space that fosters creative production. The constant flow between them enables the inhabitants living in this area to be more productive. His idea of ambivalence also focuses on the culture which brings opposing perceptions together. He theorizes all the cultural characteristics from past to the present. By evaluating Bhabha's postcolonial theories such as the postcolonial hybridity, the third space, ambivalence and in-betweenness, the study aims to indicate how Moraga tries to create such a third space by using mythology in her Chicana dramaturgy.

Moraga, playwright, poet, and thinker, rewrites the Greek myth of Medea as a Mexican lesbian, and by doing so, she underscores the ancient roots and multicultural heritage of Chicanos inhabiting the United States of America. The largest ethnic group in the Southwestern States of the United States (California, Texas, Arizona, New Mexico and Colorado), Chicanos are Mexican American people who have a history of resisting injustices caused by white supremacy. Through a feminist point of view, Moraga draws attention to the cultural dynamics and bilingualism of Chicanos in her play, The Hungry Woman: A Mexican Medea. As a lesbian activist, a feminist playwright, and a philosopher, she has championed the rights of her community throughout her life, and these concerns are at the core of her academic and works of art.

In reimagining the Euripidean tragedy ( $5^{\text {th }}$ century BC) and the ancient Greek myth of Medea, Moraga adapts it to her own culture and introduces three indigenous myths: $L a$ Llorona, Coatlicue, and The Hungry Woman. The play is set in Phoenix, Arizona, or Aztlan, the mythological homeland of the Aztecs. In the play, Medea leaves Jason, her husband, for her lesbian lover Luna, and she is exiled to the border. Jason wants the custody of his 13-yearold son Chacmool because he wants to marry a young woman. Medea, afraid that her son will become a man like his father, decides to kill her son to take revenge. Medea's act of violence brings her death as well. 
Ostracized by her own people, Moraga's Medea criticizes patriarchy and calls attention to queerness, nationhood, and indigenism. Using female characters derived from Greek and indigenous myths, Moraga creates women who defy patriarchy, colonial oppression, and heterosexism. The play underscores oppression towards women and emphasizes the cultural conditions of Chicanos as they exist in a third space. In the play, Moraga tries to show that people will continue to suffer as long as the boundaries between cultures exist. Women are the most oppressed ones in every aspect, and that new space and freedom will come forward when these borders / pressures are eliminated through cultural negotiation. 


\section{Giriş}

Melezlik kavramını farklı kültürlerin karşılaşmasıyla gerçekleşen bir kimlik/kültürel oluşum olarak değerlendiren postkolonyal (sömürge sonrası) teorisyen, edebiyat ve kültür kuramcısı Homi Bhabha, sömüren/kolonileştiren (colonizer) ve sömürülen/kolonileştirilen (colonized) iki toplumun etkileşimi ardından ortaya yeni bir alan çıktığını ifade eder. Bu yeni alan, iki farklı kültürden oluştuğu için melezdir ve üçüncü alan (third space)'ı meydana getirir. Bhabha'nın Postkolonyal Melezlik (postcolonial hybridity) teorisine dayandırdığı kuramına göre, kültürler diğer kültürlerle etkileşim haline geçtiğinde orijinal halleri kaybolur ve iki veya daha fazla kültürden doğan melez bir yapı meydana gelir. Bu durum, ilk başta toplumun kendi kimliğini kaybedişi gibi görünse de aslında değildir. Çünkü melezliğin avantaja çevrilebilmesi mümkündür. Bu avantaj, öncelikle kültürel üretim alanında kendini gösterecektir. Yeni konumlanışa adapte olmaya çalışan halk "üçüncü alanda" yer edinmek için, hiç olmadığı kadar yaratıcı olmaya başlayacak ve kültürel üretim "sıkışıklık” ve "arada kalmışlık” durumunda en verimli hali alacaktır.

Çağdaş Amerikan Tiyatrosu'nda yer alan Chicano/a (Meksika kökenli Amerikan) Tiyatrosu'nun önde gelen feminist yazarı Cherrie Moraga, 1995 yılında yazdığı The Hungry Woman: A Mexican Medea adlı oyununda Aztek ve Maya köklerine sahip olan ve İspanyol/ Avrupa kültürü ile etkileşmiş Chicanoların günümüzdeki kültürel dinamiklerine ve çift dilli yapısına feminist açıdan dikkat çekmek istemektedir. Birleşik Devletler'in Güneybatı eyaletlerindeki (California, Texas, Arizona, New Mexico ve Colorado) en büyük etnik grup olan Chicanolar, politik sebeplerden dolayı kendilerini Chicano/a $\mathrm{a}^{1}$ olarak adlandıran, kökleri bir zamanlar Orta Amerika'nın büyük bölümüne sahip olan Meksikalılara dayanan Amerikalılardır. Yazar Cherrie Moraga, 1952 yılında çok kültürlü bir geçmişin sentezi olarak varlığını sürdüren bu melez halkın mensubu olarak doğmuştur. Aktivist bir şair, lezbiyen, feminist oyun yazarı ve bir düşünür olarak kendi toplumunun haklarını yaşamı boyunca savunmuş, sanat eserlerinin ve akademik çalışmalarının eksenini bu kaygı belirlemiştir. Euripides’in İ.Ö. 5. yüzyılda yazdığı Medea oyununu kendi kültürüne göre adapte ederek yeniden yazan Moraga, üç yerli miti olan La Llorona, Coatlicue ve The Hungry Woman'1 antik Yunan miti Medea ile birleştirerek, koloni döneminin günümüzdeki etkilerini anlatmaya çalışmaktadır. Yazar, bu mitlerden aldığ kadın karakterlerle ataerkiye, sömürgeci baskılara, heteroseksüel ve erkek egemen toplum dayatmalarına meydan okuyarak, kadınların tahakküm altına alınmasına karşı çıkar. Oyun, kadınlara yapılan her türlü baskının altını çizerken, aynı zamanda da Bhabha'nın teorileştirdiği üçüncü alan içinde Amerikalı, Meksikalı ve yerli özellikler taşıyan günümüz Chicanolarının

1 İspanyolca'da kelimeyi dişil (-a) ve eril (-o) yapan ekler kelime sonunda kullanılır. Meksika kökenli Amerikalı erkekler için Chicano, kadınlar için Chicana kullanılmaktadır. Chicano Tiyatrosu, erkek egemen bir tiyatro olarak ortaya çıktığı için çalışmalarda genellikle Chicano ifadesine yer verilmektedir. Feministler ya da kadınları vurgulamak isteyenler, Chicana ifadesini özellikle kullanmaktadır. Makalede bu kültürden olan herkesi kapsayan genel ifade olan Chicano/a terimini kullanacă̆ım. 
bütün bu kültürel özellikleri geçmişten bugüne taşıdığına vurgu yapar. Moraga, kültürler arasındaki sınırlar var olduğu müddetçe halkların acı çekmeye devam edeceğini ve her açıdan en çok baskı görenin kadınlar olduğunu/olacağını oyunlarında göstermeye çalışmaktadır. Ayrıca, bu sınırlar/baskılar müzakerelerle ortadan kalktığında oluşacak yeni alan ve özgürlüklere de dikkat çekmek istemektedir.

\section{Homi Bhabha'nın Postkolonyal Melezlik/Üçüncü Alan (Postcolonial Hybridity/The Third Space) Teorisi}

“'Kolonyal söylem'yalnızca kolonyalizmi anlatan yeni bir süslü terim değildir; kültürel, düşünsel, ekonomik ya da politik süreçlerin kolonyalizmin biçimlendirilmesi, sağlamlaştırılması ve parçalanmasında birlikte iş gördüklerinin düşünüldüğü yeni bir düsünme tarzını gösterir. "Kolonyal söylem” incelemesi fikirler ile kurumların, bilgi ile iktidarın kesişmesini irdeleyerek kolonyalizm incelemelerinin kapsamını genişletmeye çalışır."

Postkolonyal teori, genel olarak sömürgeleştirilmiş toplumların kendi kültürünü devam ettirememesi ve "öteki” olarak tanımlanması gibi konulara odaklanmıştır. Bu çerçevede toplumsal, kültürel ve siyasi düzeyde evrensel normları belirleyenin Batı olması ve Batı'nın kendi kurgusuna uymayan toplumlara yönelik tutumu, postkolonyal teorinin gündemini belirlemiştir. Bu alanda akla gelen ilk üç isim Edward W. Said, Gayatri Spivak ve Homi Bhabha'dır. ${ }^{3}$ Sözü edilen teorisyenler sömürgecilik öncesi ve sonrasını, politik, sosyal, kültürel ve ekonomik dinamikler çerçevesinde incelemiş olsalar da her birinin farklı yaklaşımlara sahip olduğu belirtilmelidir.

Edebiyat, tarih ve kültür araştırmalarına sayısız katkıda bulunan Homi Bhabha, yukarıda sözü edilen alanlara ek olarak Avrupa-merkezcilik, emperyalizm, kapitalizm ve küreselleşme üzerine oldukça geniş kapsamlı ve eleştirel tahliller yapmıştır. Özellikle kültürel konumlanma üzerine öne sürdüğü tezler, Bhabha'nın bu alanda başvurulan temel referanslardan birisi olmasını sağlamıştır. Bhabha, çalışmalarında sömürgeci güçlerin sistematik bir baskınlık stratejisi oluşturduğunu, kültürel, politik, ekonomik dayanıklılıklarını sürdürebilmek ve bunları güvence altına alabilmek için sömürülen üzerinden ne gibi araçlar yarattığı üzerinde durur. Bununla birlikte, analizlerinin merkezine sömürenden çok sömürüleni yerleştirir ki bu özelliği onu Said ve Spivak’tan ayırır.

Bhabha, sömürgecilik sonrası kültürlerin birbiriyle etkileşim halinde olmasını ve bunun avantajlarını teorileştiren bir düşünür olarak, birçok eserinde karma bir yer değiştirmenin ve başka kültürlerle bütünleşmenin sömürülen açısından yarattığı gerçekliği ve üretkenliği ortaya koymaya çalışmıştır. Melez kültürel perspektiflerden yola çıkarak ele aldığı "konumlanış", üzerinde en çok çalışma yaptığı konulardan biridir. The Location of Culture ${ }^{4}$ sömürge sonrası

2 Ania Loomba, Kolonyalizm / Postkolonyalizm, çev. Mehmet Küçük (İstanbul: Ayrıntı Yayınları, 2000$), 75$.

3 Said “Orientalism”, Spivak “Can the Subaltern Speak?” ve Bhabha "The Location of Culture” adlı eserlerinde Postkolonyalizm'i geniş çaplı araştırma ve teorileriyle destekleyerek ele almışlardır.

4 Homi K Bhabha, The Location of Culture (New York: Routledge, 2006). Makalemde İngilizce aslını kullanmayı 
toplumların nasıl bir yerde konumlanmas1/konumlandırılması gerektiği üzerine ileri sürdüğü tezleri bir araya getirdiği temel eseridir. Sınır yaşamlar (border lives) ve "şimdi”nin (present) yarattığı sanatı anlattığı giriş bölümünde, bugünkü varoluşumuzu hayatta kalma hissiyatımız ve "şimdi”"nin sınırları içinde yaşamamızın belirlediğini ifade eder: "Kendimizi; farklılık ve kimliğin, geçmiş ve şimdinin, içerde ve dışardanın, dâhili ve haricinin karmaşık figürlerini üretmek üzere mekân ve zamanın melezlendiği bir geçiş anında buluruz. "„5 Bhabha için üretim ve gerçekliğin ortaya çıkacağı/çıkarılacağı zaman “şimdi”dir. Geçmişten getirilen tüm olgular, şimdi içinde melezlenmekte ve bizi başka bir boyuta taşımaktadır.

Bhabha "şimdi"de yaşayan sömürülenlerin sahip oldukları farklılıklar ve tecrübelerin avantaja dönüştürülebileceğini öne sürdüğü postkolonyal melezlik/üçüncü alan teorisini sunarken ırk, kimliğin inşası, göç, bir ulusa bağlılık, sömüren-sömürülen ilişkisi ve küresel meseleleri ele almakta ve bu çerçevede melezlik kavramına yeni bir boyut kazandırmaktadır. Bütün kültürlerin melezliğin devam eden bir süreci olduğunu ifade eden teorisyen, bu sürecin sona ermeyeceğini, eğer bu sonlanacağı fikri kabul edilirse ilerleyebilmenin imkânsız bir hal alacağını vurgular.

Bhabha, kültürleri konumlandırmaya çalışırken, sınır çizgilerinin meydana getirdiği yeniliklerden bahseder. Bhabha'nın “Kültürün sınırdaki çalışmaları, geçmiş ile şimdinin devamının parçası olmayan 'yenilik'ile bir karşılaşmaya gereksinim duyar. Kültürel dönüşümün asi bir hareketi olarak bir yenilik anlayışı yaratır. 'Geçmiş - şimdi', nostaljinin değil, gerekliliğin ve yaşamın bir parçası haline gelir" "6 ifadesinden de anlaşılacağ 1 gibi hem üçüncü alanda yaşamakta olan insanların hem de onların farklı alanlarda ortaya koydukları çalışmaların geçmiş ile şimdi arasında sıkışıp kalmayan yeni bir boyuta geçişi söz konusudur. Postkolonyalizm'e getirdiği bu farklı bakış açısı, kendisinden önceki postkolonyal kuramcıların düşüncelerinden onu ayırmış olur. Bhabha, melezliğin, başka bir ifadeyle çift değerli olmanın, iki farklı kültürün birleşmesi/karşılaşması/kültürel anlamda kesişmesi sonrasında ortaya çıkan bir yenilik/enerji/ üçüncü alan/üretkenlik/yaratıcılık olduğunu savunmaktadır. Ortaya çıkan karma kültürün “orijinal” olduğunu ve genişleyerek büyüdüğünü belirtmektedir. "Bhabha'nın postkolonyallik tartışması Sömürgecilik dönemi ile çağdaş dönem arasındaki kopuştan ziyade bir süreklilik ilişkisi olduğunu varsayar." 7 Bhabha, kültürel karşılaşma sonucunda ortaya çıkan ve süreklilik gösteren bu dinamiğin bir avantaja dönüştürülebileceğini savunmakta, “...sömürgeci bölünmeler arasındaki karşılıklılık ve müzakereleri vurgulamayı amaçlamaktadır". ${ }^{8}$

tercih ettiğim eser, Türkçeye Kültürel Konumlanış olarak çevrilmiştir. bkz. Homi K. Bhabha, Kültürel Konumlanış, çev. Tahir Uluç. İstanbul: İnsan Yayınları, 2017. Bhabha bu eserinde soyut bir dil kullandığı için kimi zaman anlaşılması güç bir çerçeve ortaya koyar. Bu sebeple, düşünürün teorilerinin daha iyi kavranabilmesi için, diğer eserleriyle birlikte görüşlerinin ele alınmasında fayda vardır.

5 Bhabha, The Location of Culture, 1-2.

6 Homi K Bhabha, The Location of Culture (New York: Routledge, 2006), 10.

7 Bart Moore-Gilbert, Postcolonial Theory: Contexts, Practices, Politics (London: New York: Verso, 2000$), 114$.

8 Moore-Gilbert, Postcolonial Theory: Contexts, Practices, Politics, 115. 
Bhabha'nın Postkolonyalizm içinde sömürüleni “özne” olarak değerlendirdiği dört temel unsur vardır: 1. Melezlik (hybridity) 2. Taklit (mimicry) 3. Farklllık (difference) 4. Duygu İkilemi (ambivalence). Bhabha'ya göre bu dört unsurun her biri, kültürel konumlanışta ve edebi, kültürel, sosyolojik birçok çalışmada orijinal bir yaratıcılık meydana getirir. Teorisyene göre bunlar ilk etapta bir dezavantaj gibi görünebilir ama özünde oldukça faydalı yönlere sahiptir. Melezlik, ortaya iki ya da daha fazla kültürün/ırkın birleşmesiyle yeni bir alan açmaktadır. Tek taraflı bir kültür, sığ ve yalın kalacaktır. Kültürel çokluluk, hangi açıdan değerlendirilirse değerlendirilsin, tek kültürlülüğe göre üstünlük sağlamaktadır. Melezlik, kendisini oluşturan kültürleri tek tek taklit etmek değildir, hepsinin karışımı ortaya daha önce hiç olmayan bir yapı çıkaracaktır. Bhabha’nın "taklit” diye belirttiği durum, "kopyalamak" ile eşdeğer tutulamamaktadır. "Kopyalama süreci asla eksiksiz ya da kusursuz olmayıp, sürecin sonunda ortaya çıkan basitçe orijinalin kusursuz bir imgesi değil, kopyanın yeniden üretildiği bağlamın etkisiyle, değişikliğe uğramış bir şeydir." 9 Üçüncü alanda yaşayan insanlar bu kopya/kopyalama sonucunda ortaya çıkardıkları çalışmalarda geçmiş ile şimdi arasında sıkışıp kalmaz, aksine onlara yeni bir boyut kazandırmış olurlar. $\mathrm{Bu}$ da "farklılık" yaratır ve genişleyen başka bir alan sunar. Kültürel kimlik sömürgeci unsurlarla iç içe geçmesinden sonra artık yalın bir hal taşımamakta, böylece melez kimlik veya özne konumu, özcü kimliğin geçerliliğini yok saymaktadır.

Sömürgeci ve sömürülen ilişkisiyle ortaya çıkan “duygu ikilemi” ise Bhabha'nın ele aldığı bir başka unsurdur. İki zit duyguyu bir arada duyumsamak olan bu ikilem, sömürülenin sömürgeciye karşı hem nefret hem de hayranlık duymasına neden olur. Onun varlığını inkâr etmeye çalışırken, kendini bunu tasdiklerken bulabilir. Bhabha burada Frantz Fanon ${ }^{10}$ ' 1 bu durumun nevrotik etkilerine dair görüşlerine yer vererek aksini iddia eder ve "öteki” olan sömürülen kimliğin sürekli bir akış halinde olduğunu, iki yerde aynı anda olma/iki duyguyu aynı anda hissetmenin sömürgeci özneye çift değerlilik kattığını ifade eder. Bu çift görüş, aynı zamanda onun direncini kuvvetlendireceği için yaratıcılığını tetikleyecek ve "yarı temsili sömürge nesnesinin tanınması" "11 na da neden olacaktır.

Homi Bhabha, teorileştirdiği üçüncü alan ve postkolonyal melezlik ile sorgulayıcı ve çok daha geniş bir kültürel anlam ardına düşmüş, sadece yansıtıcı olmayan; üretken, dinamik ve bütüncül bir "sömürülen özne"yi ele almaya çalışmıştır. Yeni üretim biçimlerine alan açmak isteyen Bhabha, birbirine eklemlenen sömürgeci ve sömürüleni mevcut sınırlarının dışına çıkarırken yenilikçi bir işbirliği sunar, sömürüleni göz ardı eden tutumlara ve onu ikincil duruma iten görüşlere karşı çıkarak, uzamsal bir politik görüşle bu teorilerini destekler.

9 Moore-Gilbert, Postcolonial Theory: Contexts, Practices, Politics, 113.

10 Frantz Fanon “Siyah Deri Beyaz Maskeler” adlı eserinde kolonileştirilmiş öznenin büyük bir arzu duyduğu beyazlığa ( burada beyazlık kendinde olmayan her şey olarak da ele alınabilir) asla ulaşamayacağını, kendisinin değersiz, siyah ve öteki olduğunu kabullendiğinden dolayı psişik bir travma yaşadığını belirtir. Bkz: Frantz Fanon, Siyah Deri Beyaz Maskeler, çev. Cahit Koytak (İstanbul: Encore Yayınevi, 2016).

11 Homi K Bhabha, The Location of Culture (New York: Routledge, 2006), 126. 


\title{
Baskıya Başkaldıran Medea'yı Yeniden Yazan Cherrie Moraga ve The Hungry Woman: A Mexican Medea Adlı Oyunu
}

\author{
“Özgürlüğü düşle, diyorum kendime. Özgürlüğ̈̈ yaz."
}

Cherrie Moraga

Chicana Feminizmi öncülerinden olarak deneyimsel anlatıma yer veren, mitolojiyi günümüz kadın sorunsalına uyarlayan, Çağdaş Chicano/a Tiyatrosu'13 na sayısız eser katmış Moraga, Amerikan tiyatrosunda sıra dışı bir sanatçı olarak kabul edilmektedir. Maria Irene Fornes, Estela Portillo Trambley, Milcha Sanchez-Scott ve Josephina Lopez'le birlikte 1980'lerin en önemli feminist tiyatro yazarları arasında yer almaktadır. ${ }^{14} 1981$ 'de Gloria Anzaldua ile beraber derlediği This Bridge Called My Back: Writings by Radical Women of Color antolojisi ${ }^{15}$ beyaz tenli olmayan kadın (colored women) yazarları bir araya getirmiştir. Eserdeki çalışmalarda Birleşik Devletler'deki kadın hareketinin Avrupa gündemi tarafından belirlendiği ve kahverengi tenli kadınların (brown women) ${ }^{16}$ bu harekette yeterince yer almadığı savunulmuştur. Bu antolojiden aldığı olumlu eleştirilerden sonra Moraga, ulusal boyutta ün kazanmıştır. ${ }^{17}$

Yazar, İngiliz bir baba ve Meksikalı bir annenin melez çocuğu olduğu için eserlerini kendi tecrübeleriyle yazmaktadır. Avrupa kökenli beyaz Amerikalılar ile aynı yaşam alanını paylaşan Meksikalıların maruz kaldığı ayrımcılığa, Chicano/a kültürünü oluşturan temel olgulara ve Orta Amerika mitlerine eserlerinde yer vermiştir. Gerek 1984’te yazmaya başladığı oyunlarında, gerekse kendi özel yaşamında hem Chicana oluşunu hem de eşcinsel kimliğini savunan yazar için kadın cinselliği, kadının toplumsal meselelerinden çok daha önce gelmektedir. Bu sebeple,

12 Cherrie Moraga, The Hungry Woman: A Mexican Medea and Heart of the Earth: A Popol Vuh Story. (USA: West End Press, 1997) x. (Makalede kaynak gösterilen İngilizce eser alıntılarının tümü, makale yazarı tarafından çevrilmiştir.)

13 Çağdaş Chicano/a Tiyatrosu, 1960’ların ortasında Meksika kökenli Amerikalıların medeni haklar hareketi olan Chicano Hareketi'nin politik mücadelesinin kültürel bir yansıması olarak ortaya çıkmış bir sanattır. Meksika kökenli Amerikalıların çalışmalarıyla kimliklerinin ve kültürel miraslarının bir simgesi haline gelen Çağdaş Chicano/a Tiyatrosu'nun kökleri, misyonerlerin Orta Amerika yerlilerini dini yönden eğitmek amacıyla başlattıkları İspanyol Tiyatrosu'na dayanmaktadır. Yerli ve İspanyol Tiyatrosu birleşiminden Meksika Tiyatrosu doğmuş, ardından da İspanyol Amerikan Tiyatrosu ortaya çıkmıştır. Meksika - ABD Savaşı’ndan sonra Birleşik Devletler'e verilen topraklarda kalan Meksikalılar bu tiyatroyu, Meksika kökenli Amerikan Tiyatrosu olarak şekillendirmişlerdir. 1965 'te Luis Valdez'in kurduğu Tarım İşçileri Tiyatrosu (El Teatro Campesino) ile Çağdaş Amerikan Tiyatrosu'nda Chicano Tiyatrosu adıyla yer almaya başlamıştır.

14 Elizabeth C. Ramirez, Chicanas/ Latinas in American Theatre: A History of Performance (USA: Indiana University Press, 2000), 85-118.

15 Cherrie Moraga ve Gloria Anzaldua, This Bridge Called My Back: Writings by Radical Women of Color (Berkeley: Third Woman Press, 1984). Moraga ve Anzaldua tarafından hazırlanan bu antoloji, çok kültürlü kadın yazarların çalışmalarından oluşmakta ve ilk Chicana feminist eleştiri eseri olarak kabul edilmektedir. Üçüncü dünya feminist eleştirisini öne çıkaran eserde, Amerika Birleşik Devletleri’nde melez kimliğe ve/veya marj dış1 kimliklere sahip azınlık unsuru olmanın sosyo-politik ve kültürel açıdan getirdiği dezavantajları konu edinen şiir ve yazılara yer verilmiştir.

16 "Brown women" (melez veya kahverengi/kızıl/yanık tenli kadınlar) birçok kültürde farklı anlamlar taşıyabilmektedir. Burada vurgulanmak istenen Latin/Hispanik kadınlardır (Latinas).

17 Jorge Huerta, Chicano Drama: Performance, Society and Myth. (UK: Cambridge University Press, 2000$), 61$. 
ilk yazılarından itibaren cinsel meselelere ve kadın sorunsalına kendi tecrübelerini de içine katarak eserlerinde yer vermiştir. Heart of the Earth: A Popol Vuh Story (1994) ve The Hungry Woman: A Mexican Medea (1995) oyunları, antik Yunan ve Orta Amerika yerlilerine (Aztek, Maya ve Toltekler) ait mitlerden izler taşımaktadır. Fütürist oyun The Hungry Woman: A Mexican Medea' da yazar, mitleri yalnızca Birleşik Devletler'deki azınlık halk olan Chicanoların sorunlarını dile getirmek için kullanmamış, aynı zamanda kadın olmanın/olamamanın evrensel meselelerini de görünür kılmak istemiştir. ${ }^{18}$

Cherrie Moraga'nın melez kimliği, The Hungry Woman: A Mexican Medea oyununu yazarken kullandığı dili de belirlemiştir. Oyun Spanglish ${ }^{19}$ kavramıyla ifade edilen İngilizce ve İspanyolca'nın iç içe geçtiği melez bir dil kullanılarak yazmıştır. Meksika kökenli Amerikalıların Hispanik miraslarına vurgu yapan yazar, oyunun en başından itibaren iki farklı kültüre ait dillerdeki bu iç içe geçmişlikle, kültürlerin birbirine karıştığını göstermeye çalışır. Böylece Chicanoların Avrupa kökenli Amerikalılarla birleşmiş yaşamları olduğunu vurgulayan yazar, Spanglish'i beyaz Amerikalıların önyargılarını ve toplumun kadınlara ve eşcinsellere olan baskıcı tutumunu eleştirmek için etkili bir araç olarak kullanmaya çalışmaktadır. Moraga, çok dilli ve çokuluslu melez kültüre odaklanarak, her türlü sınıra meydan okumakta ve sınır kültürünü de mitlerin tiyatroya aktarılması ve/veya yeniden yazılması şeklinde anlatmaktadır. Oyunun çift yönlü yapısı, iki uçlu postkolonyal içerik taşımaktadır. Hem Amerika, hem de Meksika ve yerli kültüründen birçok ögenin yer aldığı oyun, yeni bir alan yaratmaktadır.

Moraga'nın kurduğu distopik yapıda Birleşik Devletler'de sözde etnik bir iç savaş gerçekleşmiş, ardından büyük bir “devrim” yaşanmış ve neredeyse ülkenin yarısı bu devrim sonrasında birçok ulusa ayrılmıştır. Güneybatı'nın bazı kısımları Aztlan Mechicano ulusunu ve bir zamanlar Kuzey Meksika olan sınır eyaletlerini içermektedir. Yazar oyun öncesinde şu açıklamaları yapar: "Bu bağımsız milletleri kuran devrimciler, ülkenin acımasız politik ve ekonomik genişlemesine, ayn zamanda da dil, din, aile ve kabile oluşumlarl, etnik, sanatsal ve daha fazlası gibi bütün toplumsal meseleleri içeren Avrupa merkezli Amerikan kültürel egemenliğine bir son vermek için Birleşik Devletler'den ayrılmıştır. "20 Lakin oldukça "liberal” görünen devrimden yıllar sonra bir "karşıdevrim” meydana gelmiş, erkekler ve kadınlar arasında hiyerarşiler oluşmuş ve eşcinseller, homofobikler tarafından sürgüne gönderilmiştir.

18 Aycan Gürlüyer, “İki Dilli Chicano/a Kültüründe ‘Sınır' Kavramı ve Tiyatroya Aktarımı”, Dil, Kültür ve Metin: Çağdaş Yaklaşımlar içinde, Ed: İnci Bilgin Tekin (İstanbul: Doruk Yayımcılık, 2017), 132-133.

19 Spanglish (Spanish + English), İngilizce ve İspanyolca'dan oluşan birleşik bir dildir. Türkçe tam karşılığ1 olmadığı için “Íspangilizce”" kelimesi bu özel terimi belki karşılayabilir. Moraga, oyunun büyük bir bölümünü İngilizce yazmıştır fakat Chicanoların kültürel geçmişinden dolayı İspanyolca’ya da yer vermiştir. Yazar oyunda bu dili kimi zaman İngilizce ifadelerin içine kısmen yerleştirirken, kimi zamansa diyalogları tamamen bu dilde oluşturmuştur.

20 Cherrie Moraga, The Hungry Woman: A Mexican Medea and Heart of the Earth: A Popol Vuh Story (USA: West End Press, 1997), 6. 
İki perdelik oyunda dört ana karakter yer almaktadır; Medea 40'lı yaşlarının sonlarında bir ebe ve cundera $^{21}$ olarak karşımıza çıkar. Luna, Medea'nın yedi yıllık sevgilisi, 30'lu yaşlarının sonlarında bir taş ustası ve çömlek heykeltıraşıdır. Mama Sal, Medea'nın 80 yaşlarındaki büyükannesi, Chac - Mool ise Medea'nın 13 yaşındaki oğludur. Oyunda tıpkı Euripides’in Medea oyununda olduğu gibi olayları bize öncesinde anlatan bir Koro (Cihuatateo - El Coro) bulunmaktadır. Aztek mitlerinde yer alan ve doğum yaparken ölen dört savaşçı kadını temsil eden Koro, aynı zamanda dört yönü ifade eder. ${ }^{22}$ Yüzlerinde ölümü simgeleyen kuru kafa maskeleri vardır. Yalınayaktırlar ve göğüsleri çıplaktır. Geleneksel Aztek dansçıları gibi performans sergilerler. Ana karakterlerin yanı sıra Medea'nın kocası Jason ${ }^{23}$, Luna'nın kız arkadaşı Savannah, hapishanenin kadın gardiyanı, hastanenin hemşiresi gibi yan karakterler de oyunda yer almaktadır.

The Hungry Woman: A Mexican Medea oyunu 2020'lerin başında geçer. Oyun bir zamanlar Chicano ayaklanmasında lider olan Medea'nın lezbiyen olduğu için sevgilisi Luna, oğlu Chac-Mool ve büyükannesi Mama Sal ile birlikte anavatanı Aztlan' dan ${ }^{24}$ kovularak Phoenix ${ }^{25}$ Arizona'ya sürgüne gönderilmesinden birkaç yıl sonrasını anlatmaktadır. Oyunda Arizona, Gringolandia (Birleşik Devletler) ve Aztlan arasında kalan sınır bölgesini ifade eder ve bu bölge yazar tarafından "metafiziksel” olarak konumlandırılmış bir yerdir. Medea, sevgilisi, oğlu ve büyükannesi ile burada yaşamaktadır. Kocası Jason, genç bir kızla evlenmek istediği için Chac - Mool'un velayetini Medea'dan ister. Chac-Mool, Aztlan'a geri dönmek ve babasıly birlikte yaşamayı kabul eder fakat Medea, oğlunun babası gibi bir adama dönüşeceğinden korkarak onu öldürme kararı alır. Bu karar, Jason'dan intikam alma isteği ile doludur fakat kendi sonunu da getirecektir. Oğlunu öldürdükten sonra bir akıl hapishanesine kapatılan Medea,

21 İspanyolca kelime, Orta Amerika ve Maya geleneklerine göre iyileştirme teknikleri kullanan Meksikalı kadın anlamına gelmektedir.

22 Yazar Koro'da yer alan kadınların giydiği kıyafetlerin renkleriyle Kolomb-öncesi döneme gönderme yapmaktadır. O dönemde renklerin simgelediği yönler; Doğu: Kırmızı, Batı: Beyaz, Kuzey: Siyah ve Güney: Mavi'dir. Bu renkler Maya kültüründe tanrıları ve kültürel /coğrafi oluşumları simgeler. Örneğin Doğu'nun kırmızı ile simgelenmesi, güneşin doğarken kırmızı ışık yaymasından ve aynı zamanda da doğuyu temsil eden Tanrıların giydiği kıyafetlerin kırmızı oluşundan ileri gelmektedir.

23 Oyunda Medea'nın oğlunun haricinde hiç erkek karakter yer almamaktadır. Cherrie Moraga, Jason'ı Koro'da yer alan bir kadın oyuncunun canlandırmasını özellikle istemiştir.

24 Chicano/a kültüründe önemli yer tutan ve Cherrie Moraga'nın eserlerinde sıklıkla yer verdiği yitik anavatan Aztlán, sınır temalarında Chicano/a Tiyatrosu'nun vazgeçilmez olgularından biri olmuştur. Kuzeydeki Ülke/Yurt anlamına gelen Aztlán, Chicano/a halkının kendi toprakların temsil ettiğinden, özellikle de Chicano milliyetçiliğinde ve politik tartışmalarda halkı bir arada tutabilen güç ve büyük bir sembol niteliği taşımaktadır. Günümüzdeki Amerika kıtasında hangi şehir ya da bölgeleri kapsadığı kesin olarak bilinememekle birlikte, birçok eser ve kaynakta Güneybatı Amerika ve Kuzey Meksika olarak ele alınmaktadır. Genel anlamda değerlendirildiğinde, Chicanolar için Meksika'nın 1846-1848 yılları arasında süren savaş sonunda Birleşik Devletler'e bırakmak zorunda kaldığı topraklar olarak da nitelendirilebilmektedir.

25 Arizona eyaletinin başkenti "Phoenix"in adı, mitolojide her 500 yılda bir kendini yakan ve küllerinden yeniden doğan Anka Kuşu Phoenix'den gelir. bkz: (https://dictionary.cambridge.org/dictionary/english/phoenix) Moraga, simgelediği özel anlamdan dolayı oyunda bu şehri seçerek, Meksikalı Medea'nın sürgünden sonraki hayatına bir nevi gönderme yapmaktadır. 
sürekli geçmişin hayalini kurmaktadır. Psikolojik olarak yıkılmış, depresif ve alkoliktir. Işıktan saklanmakta, sürekli geçmişi düşünmekte, gerçeklerden kaçmakta, kulaklık takarak ya da uyku bantları kullanarak duyularını azaltmaya çalışmaktadır. Odasında bulunan aynalar, gerçekleri gösterdiği için onu rahatsız etmektedir:

Medea: Aynaları ört, Hemşire. Oğlumun beni böyle kızarmış gözler ve sarkan kırışıklıklarla görmesini istemiyorum. Öksüz görünüyorum. Hemşire, dinliyor musun beni? Mor klyafetleri getir. Lent ${ }^{26}$ miş gibi yapalım ve oğlumun yeniden dirilişini bekleyelim, benim kutsal oğlumun. Ancak o zaman uyuyabileceğim, ancak oğlum bana geri döndüğ̈̈nde. (Yüzünü aynaya bastırır.) Ayna soğuk, içine girilmez. Asla içine giremezsin, bir çocuk ya da bir ölü olmadıkça. İkisi de değilim, artık değilim ve henüz değilim. (Aynalarla kaplı duvara tükürür. Hemşire üstünkörü siler.) Küçük hayaletler içimde yaşıyor. Kendi genç kızlı̆̆ımın acınılası hayaleti de. Luna ile tanıştığımda her dokunuşun o kiz çocuğuna olan bir jest olduğunu hayal ederdim. ${ }^{27}$

Medea, taşustası Luna ile evinin bahçesinde tanışmıştır. Luna, Medea'nın kocası Jason'ın tuttuğu bir göçmen işçidir. Hayalinde bu sahneleri canlandırır. Medea’nın geçmişe saplantılı halde yaşadığı, artık kendini çok yaşlı ve kimsesiz hissettiği, kendi yarattığı hayaletlerle baş başa yaşadığı görülmektedir. Yunan tragedyasındaki Medea'nın “Yalnızım ben, sürgünüm”"28 ifadesinde olduğu gibi Meksikalı Medea da hayatın ve ait olmanın anlamını kaybetmiş ve sürgün edilmiştir. Yazar, oyunda bilinçli bir şekilde doğrusal (lineer) yapı kullanmaz. Bu sebeple olayların geçtiği zamanlar arasında birçok gel-git yaşanır. Medea'nın gerçekliğinde yer almayan "hayalet" karakterlerin gerçekten de geçmişte yaşayanlar/yaşananları mı yoksa Medea'nın kafasında kurduğu olayları mı canlandırdığı tam olarak bilinmediği için, oyunun anlaşılması ve ilerlemesi okuru zorlayıcı nitelikler taşımaktadır. Yazar Moraga, Medea karakterinin "yersiz, yurtsuz ve kimsesiz” oluşunu/hissedişini ve “arada kalmışlığı”nı vurgulamak için sahneler arası geçişlere bir netlik kazandırmak istememiştir. Medea, bazen sevgilisi Luna'nın hatırasıyla bazen de gerçeğiyle baş başadır. Gerçek ile hayaller birbirine karışmıştır.

Oyun, Kolomb-öncesi Mezoamerikan müziği eşliğinde açılır. Işık, Aztek Yaratılış ve Yoketme Tanrıçası Coatlicue'yu aydınlatarak başlar. Başı olmayan bir taş figürdür. Hem yaşamı/ başlangıcı hem de ölümü/bitişi simgeler. Korodaki kadınlardan Chuatateo East, bir anlatıcı rolünde bize bilgi verir: “ ...işte hikâye böyle başlar ve biter. Bir çağın başlangıcında, bir erkek çocuğunun Medea 'nın karanlı denizinden doğumuyla... "29 Ardından Chiuatateo North, Chiuatateo East'e gider ve bir hemşire kepi verir eline. North, yüzünü siyah bir maskeyle kaplar. Chiuatateo North Gardiyanı, Chiuatateo East ise Hemşire'yi canlandıracaktır.

26 Hıristiyanlıkta Paskalya'dan önce kırk gün boyunca yapılan perhiz.

27 Cherrie Moraga, The Hungry Woman: A Mexican Medea and Heart of the Earth: A Popol Vuh Story (USA: West End Press, 1997), 12.

28 Euripides, Medea Eski Yunan Tragedyaları 4, çev. Metin Balay (İstanbul: Mitos Boyut Tiyatro Yayınları, 2010), 29.

29 Cherrie Moraga, The Hungry Woman: A Mexican Medea and Heart of the Earth: A Popol Vuh Story (USA: West End Press, 1997), 9. 
Chicana yazar Moraga'nın mitlerde yer alan kadınlara eserlerinde yer vermesi hem ilham kaynağı olarak beslenmesi hem de kimlik oluşturması ve sosyal, cinsel ve politik meselelere sanatsal ve tarihsel açıdan değinebilmesini sağlaması açısından önemlidir. Feminist eleştiride mitlerin rolünün büyük olduğunu vurgulayan Maggie Humm, aşağıdaki yorumda bulunmuştur:

"Feminist mit eleştirisinin çekirdeği, geleneksel eleştirideki mit ve cinsiyet temsillerinin reddi ve çoğunlukla psikanalizlerden alınan yeni edebi terminolojinin bulunması gayretidir... Feminist eleştirmenler, Yunan - Roma mitlerinin anlatılarının bireyoluşsal olarak (ontogenetically) sadece erkek tinini yansıtan eril yapılar olduğunu ileri sürerler. Daha önceki mitolojilerde, özellikle kadın mitolojilerinde daha büyük bir güç ve yankı olduğunu savunurlar. "’30

Moraga'nın oyunu mitsel figürlerle açması, hem geçmişten geleceğe doğru bir yol haritası göstermekte hem de yaratıcı tanrıçalar ile kadın üretkenliğini ataerkinin/baskıların karşısına koymaktadır. Oyundaki melez yaklaşımı destekleyen karakterlere mitler üzerinden sembolik anlamlar yüklenmektedir. Meksika mitlerinde yer alan La Llorona (The Weeping Woman Ağlayan Kadın), sevgilisi tarafından terk edilince çocuklarını boğarak öldürmüştür. Coatlicue, yine Meksika mitlerinde yeryüzü tanrıçasıdır, bereketi simgeler. Coyolxauhqui Aztek mitlerinde Ay Tanrıça'dır ve ihanet ettiği için kendi erkek kardeşi tarafından öldürülmüştür. Aztek yaratılış mitinde yer alan The Hungry Woman ise sürekli yiyecek için ağlayan, vücudunun her yerinde birçok ağız olan kadındır. Oyunun başlığında da yer alan "aç kadın” ya da "açlık” burada oldukça semboliktir. Medea, anavatanına, sevgilisine, oğluna ya da cinselliğe aç bir kadındır ama bu açlık doyumsuzluğu değil, onun baskıdan/erkek egemen dünyanın varlığından dolayı bu doyuma bir türlü varamayışını vurgulamaktadır. Cherrie Moraga oyunun önsözünde neden oyunda mitsel kadınlara yer verdiğini açıklar:

"Benim tanrılarım kim? Benim halkım kim? Yerli tarihinin yara almış kadın hikâyeleri La Llorona, Coyolxauhqui ve Coatlicue'i keşfettiğimde iki sorunun da cevabının aynı olduğunu fark ettim. Hepsinin cinnet hallerini gösterme girişiminde bulunurken, onlara tapıyorum çünkü onların açliklarının canlı ifadesine hayran kalıyorum. Onlar, tıpkı hayallerim gibi, gerçek üzerinde ısrar ediyorlar ve bu yüzden unutkanlı̆̆a karşı açtığım savaşta benim dostlarım oluyorlar. "’31

Mitolojide korku duyulan kadınlar, yazara korku yerine ilham vermektedir. Mitolojik figürler oyunda ya perde açılışlarında tanrıça olarak yer alırlar, ya da oyun boyunca karakterler onların birçok yönünü temsil ederler. Örneğin, “Luna” İspanyolca “Ay” demektir ve oyundaki lezbiyen karakter Luna, mavi Ay tanrıçası Coyolxauhqui’yi sembolize eder.

İkinci sahnede kadın Gardiyan, kemerinde asılı kocaman hapishane anahtarlarıyla görülür. Yanında, önceden hazırlanmış bir domino oyunu vardır. Medea, kaldığı psikiyatri koğuşunda ne

30 Maggie Humm. Feminist Edebiyat Eleștirisi. Yay. haz. Gönül Bakay (İstanbul: Say Yayınları, 2002), 47.

31 Cherrie Moraga, The Hungry Woman: A Mexican Medea and Heart of the Earth: A Popol Vuh Story (USA: West End Press, 1997), x. 
olup bittiğinin gözlemlendiği, tek tarafı ayna olan duvara bakmaktadır. Sürekli "gözlemlenmek" hissi, onu gergin hale getirmiştir.

Gardiyan: (Seyircilere) Sinırda bir cezaevi psikiyatri hapishanesi. Yalnızca Chicana düşleminde hayal edilen kurmaca bir geçmişin yakın geleceği.

(Gardiyan Medea'ya doğru yürür ve çiçeklerden birini ona verir. Çiçeği okşar. Hemşire, bir tepsi yiyecekle içeri girer.)

Medea: Muftak masamdaki küçük çanlarım yok, bir mutfak masam, bir mutfak, bir kalp... ne kadar zaman oldu, Hemşire?

Hemşire: Aylar.

Medea: Yillar olacak kadar mı?

Hemşire: Henüz değil. ${ }^{32}$

Medea huzursuzdur, kendini çok bitkin, kimsesiz ve işe yaramaz hissetmektedir. Hayallerinde Jason'1, Luna'yı ve oğlu Chac-Mool'u görmekte, onlarla konuşmakta, sürekli özlem duyduğu hatıraları canlandırmaktadır. Böylece yazar Moraga, seyirci/okur için Medea'nın akıl hastanesine düşmeden önceki hayatındaki olayları da aydınlığa kavuşturmuş olur.

Sonraki sahne, bir yıl öncesini anlatmaktadır. Mekân bu kez sürgün yeri olan Phoenix, Arizona'dır. Medea ve Luna, yerlerde çer çöp olan sıkışık bir apartman dairesindedirler. Medea'ya kocası Jason'dan bir mektup gelmiştir, bazı bölümlerini Luna'ya okur:

Medea: "Bana seni hatırlatıyor, Medea. Bir zamanlar olduğun masumiyeti. Senin masum hevesini. Bana savaştan önceki Medea'yl, 'politika'nın seni...bizi değiștirmeden önceki Medea'yı hatırlatıyor. "'33

Jason, 19 yaşında bir genç kızla evlenecektir. Buradaki “masumiyetlik” genç kızın bakireliği anlamında kullanılmıştır. "Benim için kanını akıttı, tıpkı bir zamanlar senin yaptığın gibi"”34 diyen Jason, Medea'nın devrim öncesindeki masumiyetini özlemekte olduğunu ifade eder. Medea mektubu buruşturup yere $\operatorname{atar}^{35}$, Luna yerden alır ve çöp kutusuna koyar.

Medea: 'Politika'. Erkekler kadınlarda memleket sevgisi olmadı̆̆ını düşünür, ulus arzusu yalnızca erkeklere hastır. Tıpkı tanrılar gibi, ülkede kimin doğacağını, yaşayacă̆ını ve öleceğini seçerler ki ben o topraklarda her hangi bir erkek ile eşit olayım diye kanımı akıttım. Aztlan, bana nasil ihanet ettin!

Luna: Öksüz değilsin, Medea.

Medea: Ana vatanım yok. ${ }^{36}$

32 Cherrie Moraga, The Hungry Woman: A Mexican Medea and Heart of the Earth: A Popol Vuh Story (USA: West End Press, 1997), 10.

33 Moraga, The Hungry Woman: A Mexican Medea and Heart of the Earth: A Popol Vuh Story, 15.

34 Moraga, The Hungry Woman: A Mexican Medea and Heart of the Earth: A Popol Vuh Story,15.

35 Bu sembolik sahnede Jason'ın mektubunun ataerkiyi simgelediği varsayılırsa, Medea'n mektubu buruşturup yere atması ve Luna'nın (eşcinsel oluş) mektubu (kurallar, yasaklar...vs) yerden alıp çöp kutusuna koyması, Moraga'nın baskılara meydan okuyan tavrını açıkça göstermektedir. Jason'ın burada vurguladığı "masumiyet” yalnızca bakirelik değil, kadının kendi düşüncelerini bir kenara bırakıp kocasına itaat etmesi anlamına da gelmektedir.

36 Cherrie Moraga, The Hungry Woman: A Mexican Medea and Heart of the Earth: A Popol Vuh Story (USA: West End Press, 1997), 15. 
Moraga bu sahneyle kolonileştirilmiş bir milletin kendi halkına yönelik baskıcı tutumunu ve eril tahakkümün çerçevenin dışında olanları nasıl dışlayıp sürgüne gönderdiğini göstermektedir. Kolonileştirilmiş bir halk olan Chicanoların Birleşik Devletler'de dışlanan yerli kökenli bir azınlık olmalarına rağmen, kendi aralarında da kolonileştiğini ve eşcinselliğe toplumda yer verilmediğini anlatmaya çalışmaktadır. Kolonileştirme Medea’yı hem bir birey, hem de bir kadın olarak yaralamakta, onu ataerkil normların baskısı altında yaşamaya mahkûm etmektedir. Mama Sal'ın belirttiği gibi "Pan-indigenismo ${ }^{37}$ Amerika'y paramparça etmiş" "38 ve Aztlan küçücük parçalardan doğmuştur. Birlik olmak için ayrılan azınlıklar, bu kez kadınları toplumsal cinsiyetçiliğe maruz bırakmış ve “anne” Medea’yı lezbiyen sevgilisi Luna ve oğlu Chac-Mool ile birlikte sürgüne yollamıştır. Akıl hastanesine düşmeden önce yedi yıl boyunca sürgün hayatı yaşadığı Phoenix, bir zamanlar gelişmeye açık ıssız bir yer iken, "bir çeşit Çingene gettosu”,39 olmuştur.

Oyunun ilk perdesi akıl hastanesi ile sürgün yeri olan Phoenix arasında ani geçişli bir şekilde ilerler. Medea'nın oğlunu babası Jason'a vermek istemediği, evleneceği genç kadını çok kıskandığı ve Luna ile birçok problem yaşadığı gözlenir. Medea'nın sürekli bir "arada kalmışlı̆̆ı” söz konusudur. “Bu anlamda Luna 'yı sevmek sürgünü, Jason'ı sevmek ise Aztlan'l ifade eder... Jason'la yatarak Luna'ya ihanet eden Medea, Chac-Mool ve Jason'ı Luna'ya ya da ataerkil ve heteroseksüel Aztlan gerçeğini, lezbiyen feminist mitolojiye tercih eder." "40 İkinci perdenin sonunda Jason ile Medea'nın arasında geçen diyalogda Aztlan'a kabul edilmek için Medea'nın lezbiyen olduğunu inkâr etmek zorunda kaldığı görülür:

Jason: Tanrı aşkına, Medea, sen lezbiyen değilsin. Bu, gerçeği saklamaktır.

Medea: Yedi yıllık bir gerçeği saklamak mı?

Jason: Bu ilişki karşısında hiçbir şey hissetmiyorsun demiyorum ama .....sen Luna gibi değilsin. Medea: (Üzgünce) Hayır, değilim.

Jason: Yeniden düşünmeni istiyorum.

Medea: Savaştan sonra...Chac-Mool'dan önce, kendimi bu dünyada tamamen çıplak hissederdim. Bebeksi ihtiyacıyla hayatımdaki istilacı amaçsızlı̆̆ı örtbas edecek bir çocuk yoktu. Buna geri dönemem.

Jason: Dönmek zorunda değilsin.

37 Pan-American Indigenismo, yerlileri ve onların geleneklerini korumaya çalışan çeşitli politik, ekonomik ve kültürel harekettir ve 20.yy başlarında Latin Amerika'yı şekillendiren ulusal hareketlere dayanmaktadır. 1940 yılında taraftarlarınca kurumsallaştırılmıştır. 19 ülkeden delegeler Meksika’ya gelerek Inter - American Indian Institute'u kurmuşlardır. Politik görüşleri ve amaçları, Güneybatı Amerika boyunca yerlileri ve onların kültürlerini korumak, yüceltmek ve yaşam tarzlarını modernize etmek olmuştur. Detaylı bilgi için bkz: Laura Giraudo and Stephen E. Lewis, "Pan - American Indigenismo (1940-1970) New Approches to an Ongoing Debate" Latin American Perspectives Issue 186, Vol. 39 No.5 (September 2012): 3-11.

38 Cherrie Moraga, The Hungry Woman: A Mexican Medea and Heart of the Earth: A Popol Vuh Story (USA: West End Press, 1997), 23.

39 Moraga, The Hungry Woman: A Mexican Medea and Heart of the Earth: A Popol Vuh Story, 24.

40 İnci Bilgin Tekin, Myths of Oppression: Revisited in Cherrie Moraga's and Liz Lochhead's Drama (Stuttgart: Ibidem - Verlag 2012), 135. 
Medea: O zaman ben hata mi yaptım?

Jason: Hayır.

(Medea'yı kollarına alır. Öpüşürler ve sevişmeye başlarlar.) ${ }^{41}$

Medea, Jason'a (ataerkiye) boyun eğmek zorunda kalır çünkü oğlunu babasına vermedikçe Medea için ana vatanına geri dönmek imkânsız olacaktır. Ne kadar karşı koymaya çalışsa da, toplumsal normlar ve heteroseksüelliğin baskınlığı karşında yenik düşer.

İkinci perde, yine Kolomb-öncesi müzik ile başlar ve Coatlicue heykeli 1şıklandırılır. Medea sahnede Coatlicue olarak görülür. Cihuatateo East, Medea'nın beline önlük bağlar, North ise eline bir süpürge verir. Koro, Coatlicue yani Yaratan ve Yokeden Tanrıça'nın hamile olduğunu belirtir. Luna bu kez karşımıza Coyalxauhqui olarak çıkar:

Coyalxauhqui: Bana ihanet ettin, Anne.

Cihuatateo East: Böylece, arkadaşları Dört Yüz Yıldız ile birlikte, Coyolxauhqui Ana Tanriça'yı öldürmek için bir araya gelir.

Koro: Oğlunun ışı̆̆ı, kızının aydınlı̆̆ını gölgede bırakacak. Seni sarılışının sıcă̆ıyla ateşin altında birakacak. ${ }^{42}$

O sırada Aztek Güneş Tanrısı Huitzilopotchli doğar. Tanrıyı Chac-Mool canlandırmaktadır. Huitzilopotchli ve Coyalxauhqui, göklerde kavga ederler. Huitzilopotchli, kız kardeşinin başını keser:

Huitzilopotchli: Şu ellerimin arasında kanayan kız kardeşimin ay yüzü mü? Seni bir yabancı ve kadın olarak, evin olacak karanlığın o kocaman deliğine sürgün ediyorum.

(Huitzilopotchli, başı göklere firlatır. Herkes Ay'ın karanlık göğe yükselişini izler.)

Coatlicue: La Luna!

Cihuatateo East: Işte böylece bütün geceler başlar ve biter. ${ }^{43}$

Ani bir geçişle psikiyatri kliniği ikinci perdenin birinci sahnesi olarak yer alır. Medea korkuluklu camın önünde durmaktadır. Ay 1şığı, parmaklıkların gölgesini yüzüne düşürmektedir. Hemşire Medea'yı izler:

Hemşire: Bu gece Ay çok güzeldi, gördün mü?

Medea: Hayır Luna. Hayır Luna.

Hemşire: (Gardiyana). Sabahtan beri dehşet içinde yürüyor. Klz arkadaşı gelmedi. ${ }^{44}$

Medea, hayallere dalar. Annesiyle olanlar gözünde canlanır. Annesi Medea'dan erkek kardeşi ne isterse almasına izin vermesini söylemektedir. Medea ise "Çünkü ailedeki tek erkek...Çünkü

41 Cherrie Moraga, The Hungry Woman: A Mexican Medea and Heart of the Earth: A Popol Vuh Story (USA: West End Press, 1997), 54.

42 Moraga, The Hungry Woman: A Mexican Medea and Heart of the Earth: A Popol Vuh Story, 56.

43 Cherrie Moraga, The Hungry Woman: A Mexican Medea and Heart of the Earth: A Popol Vuh Story, (USA: West End Press, 1997), 57.

44 Moraga, The Hungry Woman: A Mexican Medea and Heart of the Earth: A Popol Vuh Story, 57. 
Tanrı, onu evimize tek parça ve akıllı olarak getirdiği için bize iyilik yaptı." ${ }^{45}$ diyerek karş1 çıkar. Medea hayallerin arasından çıkıp Hemşire'ye Luna'nın gelmediğini yineler. O sırada Gardiyan, Luna'nın sınırda tutuklandığını duyurur. Yine ani bir geçişle sorgu odasında elleri bağlı bir şekilde Luna oturmakta, kocaman bir 1şık, yüzüne tutulmaktadır:

\author{
Sinır Gardiyanı: Neden sınırı geçtin? \\ Luna: Onun yanina gidiyordum. \\ Sinır Gardiyanı: Kimin yanına? \\ Luna: Aklım başımda değildi... Hiç kimsenin. Hastayı ziyaret edecektim... \\ (...) \\ Sinır Gardiyanı: Çalı̧̧ma iznin yok...Bunun yasal olmadığını biliyordun. \\ Luna: Aztlan'ı özlemiştim. \\ (...) \\ Sinır Gardiyanı: Neden müzeye girdin? \\ Luna: Onlarl serbest birakmak istiyordum. \\ Sinir Gardiyanı: Kimi? \\ Luna: Şu küçük kadın figürlerini. Şu küçük memeli, kalın kalçalı...kadınları. ${ }^{46}$
}

Medea Luna'nın yanına gelir, Gardiyan dışarı çıktığında sevişirler ve tekrar geri döndüğünde ona yakalanırlar: "Demek lezbiyen olduğunuzu itiraf ediyorsunuz. "'47 Medea ve Luna panikler. Sınır Gardiyanı Luna’ya bunu itiraf edip etmeyeceğini sorar. Luna, Medea'yla yatakta sevişirken Jason'ın onları yakaladığını anlatır. Medea ve Jason kavga etmişler ve sonrasında da Medea ceza olarak sürgüne gönderilmiştir. Bu olaydan sonra da hiçbir şey eskisi gibi olmamıştır. Sonraki sahnede Medea ve oğlu Chac - Mool görünür. Chac - Mool, çok sevdiği Luna onları terk ettiği için Medea'yı suçlamaktadır. Medea, Luna'nın gitmesini Chac-Mool'u korumak için yaptığını söyler ama bu onu ikna etmeye yetmez. Kendisini, Meda'nın sırf kendini tatmin etmek için koruyup kolladığını söyler:

Medea: Evet. Bu bir suç mu? Geri gidebilir ve her şeye yeniden başlayabiliriz.

Chac-Mool: ... Onu böylece terk mi ettin, Anne? Bunca zamandan sonra? Babamı sevmiyorsun bile. Seviyor musun?

Medea: Hayır...

Chac-Mool: Sen savaşçı bir kadındın, Anne. Sen lanet olası bir kahramandın!...

Medea: Neredeyse elli yaşındayım. Savaşmaktan bıktım. Eve dönmek istiyorum. ${ }^{48}$

Medea yılgın, yorgun ve Luna’yı kaybetmenin hüznü içinde yaşamaya devam etmeye çalışmaktadır. Jason, Medea'yı oğlunu vermesi için yine ikna etmeye gelmiştir. Medea, oğlunu vermeyi kabul etmez:

45 Moraga, The Hungry Woman: A Mexican Medea and Heart of the Earth: A Popol Vuh Story, 58.

46 Moraga, The Hungry Woman: A Mexican Medea and Heart of the Earth: A Popol Vuh Story, 58-59.

47 Moraga, The Hungry Woman: A Mexican Medea and Heart of the Earth: A Popol Vuh Story, 62.

48 Cherrie Moraga, The Hungry Woman: A Mexican Medea and Heart of the Earth: A Popol Vuh Story (USA: West End Press, 1997), 67. 
Medea: Evrakları geri yolladım çünkü kabul edilir gibi değillerdi. Şartlarımı göz ardı etmişsin. Jason: Anlaşmada bulunacak durumda değilsin, Medea... Senin bakımını üstleneceğim, anneannenin de.

Medea: Ben senin fahişen değilim, Bayım. Aztlan'da kocasız bir kadın hiçtir.

Jason: O zaman istersen burada kal. Senin kararın.

Medea: O zaman ikimiz de kallyoruz. Chac-Mool bensiz hiçbir yere gitmeyecek.

Jason: Medea, seni istemiyorum.

Medea: Ben de seni istemiyorum, ama yurduma dizlerimin üstünde geri dönmeyeceğim. Devrimle birlikte Katoliklik'i bıraktığımızı düşünmüş̧ı̈̈m. ${ }^{49}$

Medea, Jason'1 kovar. Ondan asla kurtulamayacağını söyler. Fakat Jason, boşanmanın mahkeme kararıyla gerçekleşmek üzere olduğuna ve oğlunun verasetini aldığına dair evrakları masanın üzerine koyup gider. Chac-Mool, bir süre sonra babasının yanına Aztlan'a temelli dönmeye karar verir. Bu karar Medea’yı çıldırtır:

Medea: (Omuzlarından yakalayarak) Sen benim toprağımsın, oğlum. Bunu görmüyor musun? Sen benim vatanımsin!

Chac-Mool: Bunun babaminkinden ne farkl var?

Medea: Çünkü ben yerliyim, o değil. Ve ben senin annenim!

Chac-Mool: Bu benim hatam değil!

(Medea donakalır. $)^{50}$

Medea, yedi yıl boyunca sürgün hayatında fedakârlıklarla baktığı oğlundan böylesine hiddetli bir ifade duyunca yıkılır. Onu tamamen kaybettiğini anlamıştır. Oğlundan ayrılacağı son akşam ona içine zehir koyduğu bir içecek hazırlar ve kendi elleriyle içirir. Chac-Mool Medea'nın kollarında can verir. Vatansız, topraksız kalmamak ve Jason'dan intikam almak için oğlunun canına kıymıştır. Artık savaşacak gücü de kalmamıştır ve bütün yenilgileri kabul edip hayata onu bağlayan tek sebep olan oğlunu da öldürür.

Cherrie Moraga, La Llorona mitini ve Meksikalı Medea'yı birleştirdiğinde kendi oğullarını öldürmelerini bir çeşit intihar olarak değerlendirir çünkü bir anne her zaman oğlunun bir parçasıdır:

“La Lorona çocuklarını öldürdüğünde erkek tanımlı bir Meksikalı anneliği öldürüyor... ataerkil anneliği öldürme arzusu ki bir başka Meksika miti 'Huitzilopotchli'nin Doğumu'ile bağlantılıdır. Bu Meksika miti, yaşlı annesi Coatlicue'nin hamileliğini ögrrendiğinde öldürmeye teşebbüs eden Aztek Ay Tanrıçası Coyolxauhqui'yi anlatır. Bu cinayetle kölelik, insanlığın yıkımını ve emperyalizmi (kısaca ataerkiyi) temsil eden Savaş Tanrısı Huitzilopotchli'nin doğumunu engellemeyi umar. Başarısız olur, kardeşi Huitzilopotchli tarafindan başı kesilerek öldürülür ve Ay olarak karanlığa mahkûm edilir. Bu antik mit, Meksikalı kadınlara şunu hatırlatır ki, bizim tarafimızdan tanımlandığ sanılan bir anne-kadın yoktur. Bizim asla tanım

49 Moraga, The Hungry Woman: A Mexican Medea and Heart of the Earth: A Popol Vuh Story, 68.

50 Cherrie Moraga, The Hungry Woman: A Mexican Medea and Heart of the Earth: A Popol Vuh Story, (USA: West End Press, 1997), 85. 
yapacak bir gücümüz olmadı. Ölü çocuklarımızın peşinde dolaşmıyoruz, asıl kayıp kendimizi, kayıp cinselliğimizi, kayıp maneviyatımızı, kayıp bilgeliğimizi arıyoruz." ${ }^{51}$

Kendini ifade edecek fırsatın verilmediği devrim sonrası dünyada ve ataerkinin dışlayıcı kurallarıyla örülü sürgün hayatında Medea, kendini sıkışmış kalmış bir beden/ruh olarak görmekte, tek çözümü de oğlunu yani bir nevi “kendisini” öldürmekte bulmaktadır.

Oyunun son sahnesi psikiyatri hastanesidir. Luna geri gelmiştir. Rüyasında Medea'nın kendini doğurduğunu gördüğünü söyler. Sembolik rüya, Medea'nın hastanedeki ruh halinin kendisi için yeni bir doğum olduğu anlamına gelmektedir. Medea Luna'y1 artık istemez ve gitmesini söyler. Luna çıkar. Oğlu Chac-Mool gelir, Medea onun hayalet olup olmadığından emin olamaz. "Ĕ̆er yaşıyorsan, ben neden buradayım? Hiçbir suç işlemedim...Neden?" 52 diye oğluna sorar. Chac-Mool onun bir hastanede olduğunu ve onu Aztlan'a götürmeye geldiğini söyler. Camdan Ay’a bakmasını ister, yatağına geri götürür ve bir içecek verir. Medea içer ve sonsuz bir uykuya dalar. Oğlu kollarında ölürken yaratılan "pieta"53 imgesi, bu kez kendisi oğlunun kollarındayken ortaya çıkar. Medea son nefesini verir, yalnızca ay ışığı etrafı aydınlatır, Koro ay 1şığında sessizce dans ederken oyun biter.

Medea bir akıl hastanesinde kalmaktadır ve hastane, Birleşik Devletlerle Aztlan arasındaki “metafiziksel bir sınır”da yer almaktadır. Sahip olunan kimliğin, kültürel geçmişin ve öz değerlerin politik bir tutumla sahiplenilmesi olarak düşünülmesi gereken bir sınırda olma kimliği, aynı zamanda Anglo-Amerikan kültüründen kopmadan ama daha çok Meksika kültürünü ve yerli geçmişini içinde barındıran melez bir olgudur. Alfred Artega, Chicano Poetics: Heterotext and Hybridities adlı eserinde sınır ifadesini aşağıdaki gibi değerlendirmiştir:

"Sinır, nihayetinde, Chicanoların doğmasına neden olan ulusal ayırım hattıdır. Bu, hattı geçtikleri ya da geçmek zorunda bırakıldıkları için değil, sınır bölgesinde hattın meydana getirdiği uluslar arasında yaşamalarından dolayıdır. Sinır, Chicano kimliğinin, devletin yalın ve mutlak tedbirine karşı oluşturulması anlamına gelir. Sinır topraklarında Chicano olmak, kendini ulus, kültür, dil, ırk, etnisite gibi mücadele veren tanımlamalar arasından meydana getirmektir",54

Artega'nın bu açıklamasından da anlaşılacağı gibi, sınır ve Chicano kavramları, mücadele dolu bir geçmişle iç içedir. Birleşik Devletler ve Meksika sınırındaki Chicano/a yazınsal ve kültürel sınır kavramlarını Borderlands La Frontera adlı kitabında ele alan Chicana feminist düşünür ve yazar Gloria Anzaldua, kitabının önsözünde "Ben bir sınır kadınıyım. İki kültür

51 Maria Antonia Oliver-Rotger, "VG Interview: Cherrie Moraga" Voices From the Gaps: University of Minnesota (Jan. 2000), 12-13.

52 Moraga, The Hungry Woman: A Mexican Medea and Heart of the Earth: A Popol Vuh Story, 98.

53 Meryem'in kucağında ölü İsa'yı tuttuğu tasvir. Aynı zamanda Michelangelo'nun bugün Vatikan'da bulunan aynı tasvirdeki heykelinin adı.

54 Alfred Arteaga, Chicano Poetics: Heterotexts and Hybridities (Cambridge \& New York: Cambridge University Press, 1997), 9-10. 
arasında büyüdüm: Meksika (baskın bir yerli etkisiyle) ve Anglo kültürü (bize ait topraklarımızın sömürgeleştirilmiş insanlarından birisi olarak). " 55 (19) ifadesiyle sınır insanı olmakla melez/ Chicana oluşunu açıklamıştır. Anzaldua'ya göre "Sınırlar, güvenli ve güvensiz olan yerleri belirlemek, bizi onlardan ayırmak için çizilmiştir. Bir sınır, bölen bir hattır...Alıkoyulan ve yasaklananlar, üzerinde yaşayanlardır" ${ }^{\text {"56 }}$. Sınırın insan psikolojisinde, kimliğinde ve kültüre bakış açısında birçok değişim meydana getirdiğini vurgulayan Anzaldua, çok kültürlü bir kimliğe sahip olmanın zaferlerini ifade ederken Birleşik Devletler'in ve kendisi gibi olmayanları reddedenlerin tutumunu şiddetle eleştirmektedir. Yazar Moraga da yazdığı bu oyunda çok kültürlü ve çok dilli bir geçmişin gururundan bahsederken aynı zamanda postkolonyal bir feminist yaklaşımla "sınırda olmak", "sınırda kadın olmak" ve "sınırda lezbiyen kadın olmak" temalarının altını kalın çizgilerle çizer. Bütün bu sınırları ve arada kalmışlıkları gerek fiziksel/ metafiziksel, gerekse psikolojik olarak Medea ve Luna gibi dışlanmış ve sürgüne gönderilmiş karakterler üzerinden anlatıp toplumsal cinsiyetçiliği eleştirir ve ataerkinin baskısıyla kimliğini yitirmek zorunda bırakılan kadınları birçok kültürden beslendiği mitlerle görünür kılmaya çalışır.

\section{Sonuç}

Çağdaş kuramcı Homi Bhabha kültürleri konumlandırmaya çalışırken, sınır çizgilerinin ve melezliğin meydana getirdiği yenilikleri ele alır. Bhabha'nın çalışmaları, geçmiş ile şimdinin devamının parçası olmayan "yenilik" ile bir karşılaşmaya gereksinim duymaktadır. Üçüncü alanda yaşamakta olan insanların ve eserlerinin geçmiş ile şimdi arasında sıkışıp kalmadığı "yeni” bir boyut söz konusudur. Chicanolar için de bu yenilikler sınır çizgisi çizildikten sonra onlarca yıl içinde şekil almış, söz konusu “üçüncü alan”daki kültürel iç içe geçiş, Birleşik Devletler'de Chicano/a Tiyatrosu gibi farklı sanatların ve düşüncelerin ortaya çıkmasına neden olmuştur.

Cherrie Moraga, Medea’y1 lezbiyen bir kimlikte yaratarak erkek egemen Meksika / Chicano kültürüne, heteroseksist tutumlara ve kadını cinsel anlamda hapsetmeye çalışan tüm geleneksel fikirlere/merkezi düşüncelere karşı meydan okumaktadır. Ayrıca günümüz feminist anlayışa beyaz ve heteroseksüel kadınların hâkim oluşuna da bu şekilde bir eleştiri getirmektedir. Cinsiyetçi sömürüyü ele aldığ 1 eseri Feminism is for Everybody: Passionate Politics'de Bell Hooks'un belirttiği “Ana akım kitle iletişim araçları, feminist hareketin neyi temsil ettiğini göstermek için her zaman heteroseksüel bir kadın seçti-ne kadar heteroseksüel olursa o kadar iyidir. "57 görüşünü desteklemektedir. Dışlanan Chicana kadınlardan olarak, kendi yaşadığ 1 lezbiyen deneyimlerden de faydalanıp bunları birinci elden yazarak toplumun istediği gibi heteroseksüel kadın olmama hakkının savunusunu yapmaktadır. Medea'nın lezbiyen olması, onun topluma karşı birçok kez yabancılaşmasına neden olur. Euripides' in oyunundaki "yabancı"

55 Gloria Anzaldúa, Borderlands La Frontera: The New Mestiza (San Francisco: Aunt Lute Books, 1999), 19.

56 Anzaldúa, Borderlands La Frontera: The New Mestiza, 25.

57 Bell Hooks, Feminism is for Everybody: Passionate Politics (Canada: South End Press, 2000), 97. 
ve “öteki” Medea, Cherrie Moraga’nın oyununda hem ırksal hem de cinsel anlamda ötekidir ve bunu saklamaya çalışmaz. Moraga, düzyazı eserlerinde de her firsatta cinsel kimliğini vurgular ve ana akımı eleştirir: "Biz beyaz feminist hareketin beyaz olmayan kadınlarıyız / Biz kendi kültürümüzün insanları arasındaki feministleriz / Biz, heteroseksüeller arasında lezbiyeniz / Bu köprüyü de kendimizi adlandırarak ve kendi hikâyelerimizi kendi kelimelerimizle anlatarak kuruyoruz. " 58 Moraga, Chicana bir kadın olmanın Birleşik Devletler'de dışlanmak için yeterli bir sebep iken, lezbiyen bir Chicana kadın olmanın ise toptan reddedilişe neden olduğunu ifade eder.

Çağdaş Amerikan Tiyatrosu içinde yer alan The Hungry Woman: A Mexican Medea adlı oyunda yazar Moraga'nın günümüz seyircisi/okurlarına yerli ve Hispanik kültürel ögelere sahip Amerikalı melez azınlık Chicanoların hem Amerikalılar tarafından baskı altına alınmasının, hem de kolonileştirilmiş bir halk olarak kendi aralarında da kolonileşmelerinin eleştirisi vardır. Lezbiyen başkarakter Meksikalı Medea ile toplumdaki heteroseksüel tutumlara dikkat çeken Moraga, kültürler ve cinsel tercihler arasındaki sınırlar var olduğu müddetçe bireyin kişilik kazanamayacağını ve toplumsal değerlerin yiteceğini göstermeye çalışır. Ataerkinin kadınlar üzerindeki baskısını ve heteroseksüel norm dayatmalarının insanları "sürgün” ettiğini vurgular. Oyun geçmiş ile şimdi arasındadır, lineer bir akış söz konusu değildir. Eserin bu yapı içinde kurulma sebebi, melez halkın geçmiş ile gelecek arasında birbiri içine geçmiş ve devam eden bir bilinç oluşturmasından dolayıdır. Moraga, aynı zamanda Aristotelyen batıcı anlayış olan üç birlik kuralını yıkarak karakterleri sayısız zaman ve mekânda dolaştırarak sınırları genişletir. Sömürgeci ve heteroseksüel baskılara meydan okuyan yazar, yerli miti olan The Hungry Woman'1 Yunan miti Medea ile birleştirmesiyle oyunun kendisini de melez hale getirmiş ve baskı görmüş bütün halklara ve kadınlara seslenen evrensel temalara yer vermiştir. Binlerce yıl önce yazılmış bir tragedyayı kendi kökleri ve günümüz dinamikleriyle birleştiren, bir meydan okuma ve direniş olarak bize sunan yazarın bu eseri, hem feminizme getirdiği farklı bakış açısı, hem azınlık halklara dikkat çekişi, hem de ataerkiyi ve beyaz olanlar/olmayanlar ayrımcılığını eleştirmesi açısından dikkat çekicidir. Oyun, melez oluşumlara hem sanatsal hem de kuramsal anlamda farklı bakış açıları katmakta ve çağdaş tiyatronun çok kültürlü yönüne vurgu yapmaktadır.

Homi Bhabha'nın Postkolonyal Melezlik/Üçüncü Alan teorisine örnek olarak seçtiğimiz eser The Hungry Woman: A Mexican Medea, Euripides'in Medea eserinin yalnızca bir yeniden yazımı değil, üçüncü alan içinde yer alan feminist, politik ve mitsel bir eserdir. Oyun, Bhabha'nın kolonileştiren/kolonileşenin sabit bir kültürel kimlik taşımadığı, bir uzlaşma içinde üçüncü alan oluşturduğunu belirttiği arada kalmışlık teorisinin birçok izini taşımaktadır. Meksikalı Medea karakterinin insanlar, sınırlar, erkekler, kadınlar, hayaller, gerçekler, cinsel tercihler... vs. arasında

58 Cherrie Moraga ve Gloria Anzaldua, This Bridge Called My Back: Writings by Radical Women of Color (Berkeley: Third Woman Press, 1984), 23. 
kalması, mekânsal veya zamansal açıdan onun kimliğini yok eder gibi görünse de aslında Moraga, mitlerle bir bütün haline getirdiği oyununda Medea'yı üçüncü alan içine yerleştirerek politik, kültürel ve cinsel anlamda dikkat çekmeye çalışmaktadır. Melez Chicanoların köklerinin hem Aztek/Mayalara kadar gitmesi, hem de Avrupa kökenli atalarının olması, onların Bhabha'nın bahsettiği yaratıcı ve üretken alanda yer almalarına neden olmaktadır.

\section{KAYNAKÇA / BIBLIOGRAPHY}

Arteaga, Alfred. Chicano Poetics: Heterotexts and Hybridities, Cambridge \& New York: Cambridge University Press, 1997.

Anzaldúa, Gloria. Borderlands La Frontera: The New Mestiza. San Francisco: Aunt Lute Books,1999.

Bhabha, Homi K. The Location of Culture. New York: Routledge, 2006.

Euripides, Medea, Eski Yunan Tragedyaları 4, çev. Metin Balay. İstanbul: Mitos Boyut Tiyatro Yayınları, 2010.

Gürlüyer, Aycan. “İki Dilli Chicano/a Kültüründe ‘Sınır' Kavramı ve Tiyatroya Aktarımı”. Dil, Kültür ve Metin: Çağdaş Yaklaşımlar. Editör İnci Bilgin Tekin, 121-140. İstanbul: Doruk Yayımcılık, 2017.

Hooks, Bell. Feminism is for Everybody: Passionate Politics. Canada: South End Press, 2000.

Huerta, Jorge. Chicano Drama: Performance, Society and Myth. UK: Cambridge University Press, 2000.

Humm, Maggie. Feminist Edebiyat Eleștirisi. Yay. Haz. Gönül Bakay. İstanbul: Say Yayınları, 2002.

Loomba, Ania. Kolonyalizm / Postkolonyalizm, çev. Mehmet Küçük. İstanbul: Ayrıntı Yayınları, 2000.

Moore-Gilbert, Bart. Postcolonial Theory: Contexts, Practices, Politics. London: New York: Verso, 2000.

Moraga, Cherrie. The Hungry Woman: A Mexican Medea and Heart of the Earth: A Popol Vuh Story. USA: West End Press, 1997.

Moraga, Cherrie, ve Gloria Anzaldua, eds. This Bridge Called My Back: Writings by Radical Women of Color. Berkeley: Third Woman Press, 1984.

Oliver-Rotger, Maria Antonia. "VG Interview: Cherrie Moraga", Voices From the Gaps: University of Minnesota (Jan. 2000), 1-16. Erişim 12 Mayıs 2018. https://conservancy.umn.edu/bitstream/ handle/11299/166372/VG\%20Interview\%20Cherrie\%20Moraga.pdf;sequence=1

Ramirez, Elizabeth C. Chicanas/ Latinas in American Theatre: A History of Performance. USA: Indiana University Press, 2000.

Tekin, İnci Bilgin. Myths of Oppression: Revisited in Cherrie Moraga's and Liz Lochhead's Drama. Stuttgart: Ibidem-Verlag, 2012. 
